\title{
Concepção sobre surdez na perspectiva de mães de crianças surdas
}

\author{
Gabriela de Paula Teixeira1, Angélica Bronzatto de Paiva e Silva², Maria Cecília Marconi Pinheiro Lima³
}

\begin{abstract}
RESUMO
O objetivo do estudo foi conhecer a concepção de surdez de mães ouvintes de crianças surdas, identificar as informações que receberam a respeito das diferentes abordagens educacionais de surdos e a forma de comunicação que estão privilegiando na interação com seus filhos. Com base em uma abordagem qualitativa, foram entrevistadas sete mães de crianças com surdez, de grau severo a profundo, acompanhadas por uma equipe interdisciplinar de uma instituição bilíngue. $\mathrm{Na}$ análise de dados observou-se que nenhuma participante recebeu informações sobre surdez e as possibilidades de (re)habilitação após o diagnóstico. A maioria não escolheu a instituição frequentada e, inicialmente, não apresentava uma concepção de surdez, com exceção de uma mãe, com uma concepção sócio-antropológica de surdez; e a forma de comunicação entre as mães e as crianças se diferenciava de acordo com o grau de surdez. Concluiu-se que a maioria das participantes não reconhece a ideologia da identidade surda.
\end{abstract}

Descritores: Surdez; Pais; Crianças Surdas; Educação de Surdos

\section{Conception of deafness in the perspective of mothers of deaf children}

\begin{abstract}
Our aims were to know the conception of deafness in hearing mothers of deaf children; the information they received about the educational approach of the deaf; and the manner of communication they choose with the children. Qualitative study, with a semi structured interview ending with the saturation of informations. The sample was composed by seven mothers and it was used the technique of content analysis. The data showed that none of the participants received information about deafness and the possibilities of (re)habilitation following diagnosis. The majority of the mothers did not choose the institution the child would attend and did not have a conception of deafness, except one mother that showed a socio-anthropological conception. The form of communication among mothers and their children varied according to the degree of the child's deafness. Conclusion: The majority of the participants did not recognize the ideology of deaf identity.
\end{abstract}

Descriptors: Deafness; Mothers; Education of Hearing Disabled; Rehabilitation of Hearing impaired; Special Education.

${ }^{1}$ Fonoaudióloga pela Universidade Estadual de Campinas (UNICAMP), Campinas, SP, Brasil.

${ }^{2}$ Psicóloga pela Pontifícia Universidade Católica de Campinas (PUC- Campinas), Campinas, SP, Brasil.

${ }^{3}$ Doutora em Ciências Médicas pela Universidade Estadual de Campinas (UNICAMP), Campinas, SP, Brasil. 


\section{Introdução}

O diagnóstico da surdez em um membro da família leva à reestruturação do sistema familiar como um todo, dependendo da forma com que a família enfrenta a deficiência auditiva e de sua capacidade de organizar um ambiente que favoreça ou não o desenvolvimento real e potencial da criança ${ }^{1}$. No processo de diagnóstico, surgem nos pais, diferentes reações, sendo alguns sentimentos descritos, tais como: tristeza, ansiedade, angústia, dor pela perda do filho idealizado ${ }^{2,3}$.

Adequadas orientações aos familiares frente à surdez são importantes para que estes estejam preparados e conscientes de seu papel no desenvolvimento da criança e para que obtenham o aproveitamento de todas as oportunidades geradas no lar ${ }^{4}$. Desta forma, o sucesso linguístico da criança surda está relacionado ao diagnóstico precoce e às intervenções adequadas ${ }^{5} \mathrm{e}$ seu desenvolvimento emocional e social é influenciado pela forma como a família encara esse diagnóstico de surdez¹.

A capacidade que uma família tem de se comunicar é claramente fundamental para que esta seja funcional, propiciando trocas de sentimentos, desenvolvimento de segurança e autoconfiança entre seus membros ${ }^{1}$. A forma de comunicação entre sujeitos surdos e ouvintes, principalmente no processo educacional, sofreu modificações ao longo da história, sendo que as diferentes concepções metodológicas de ensino dos surdos surgiram a partir do século XVI, junto aos seus primeiros educadores . $^{6}$

Os profissionais que trabalham nas áreas da educação, psicologia, filosofia e outras ciências estão cientes de como um conceito ou uma idéia sobre uma pessoa com dimensões físicas, psicológicas e sociais pode afetar a maneira como ela é tratada, vista, e até mesmo educada. Assim, ao percorrer a literatura, observam-se concepções diferentes de surdez, as quais parecem decorrer de imagens distintas de surdez e de surdos.

O Oralismo concebe a surdez como um déficit e o indivíduo surdo como uma pessoa que necessita desenvolver a língua oral. Esta abordagem é denominada como clínico-terapêutica e se relaciona a um ponto de vista de caráter médico, sendo o surdo visto como deficiente auditivo, com o trabalho terapêutico baseado na oralização. 0 bilinguismo, por sua vez, relaciona-se à concepção sócio-antropológica e nesta o sujeito surdo é visto como "diferente" do ouvinte, uma vez que seu principal canal de comunicação com o mundo e com as pessoas é o visogestual, o que implica na aceitação da Língua de Sinais e da comunidade surda, na qual se utiliza uma língua minoritária?.

Frente ao diagnóstico de deficiência de seu filho, os pais passam a apresentar reações e concepções de surdez que podem ser influenciadas por fatores como o conhecimento pregresso da família; a forma como foram informados sobre 0 diagnóstico pelos profissionais envolvidos em tal processo; suas crenças e idéias ${ }^{3}$.

Sendo assim, pretende-se neste trabalho conhecer as concepções de surdez na perspectiva de mães ouvintes com filhos surdos, atendidos de forma interdisciplinar dentro da abordagem educacional bilíngue; identificar as informações que as mães receberam a respeito das diferentes abordagens da educação de surdos, os motivos que as nortearam na escolha de uma ou outra abordagem e a forma de comunicação que estão privilegiando na interação com seus filhos surdos.

\section{Metodologia}

O presente estudo caracteriza-se por uma abordagem qualitativa por ser um método que envolve uma abordagem naturalista, interpretativa, ocorre no "setting" natural e busca entender ou interpretar os fenômenos em termos dos significados que as pessoas a eles conferem ${ }^{8}$. Na medida em que este estudo busca identificar as concepções que as mães de crianças surdas constroem sobre a surdez, considerou-se a abordagem qualitativa como o método mais adequado para o desenvolvimento desse estudo.

O estudo foi aprovado pelo Comitê de Ética em Pesquisa de uma Universidade Estadual do Estado de São Paulo sob o parecer de número 375/2011.

Participaram deste estudo mães de crianças com surdez de grau severo a profundo acompanhadas por uma equipe interdisciplinar de um Centro de Estudos e Pesquisas em Reabilitação do Estado de São Paulo há, no mínimo, um ano.

Para a seleção dos participantes foram consideradas todas as crianças atendidas na instituição, levando-se em consideração os critérios adotados: mães ouvintes de crianças com surdez severa e/ou profunda; seus filhos terem atendimento interdisciplinar na instituição há pelo menos um ano e a assinatura do Termo de Consentimento Livre e Esclarecido (TCLE). Foram excluídas, da mesma forma, as mães surdas e/ou de crianças com surdez de grau leve a moderado, crianças surdas com outras deficiências associadas, que frequentam a instituição a menos de um ano e os pais que não assinaram o TCLE.

Realizada a seleção nos arquivos da instituição das possíveis candidatas à participação no estudo, a pesquisadora foi contatando individualmente as mães, de acordo com a sua disponibilidade de horário, para explicação do estudo e 
obtenção do consentimento livre e assistido. Após o aceite das mães, foi agendada uma entrevista em horário disponível para elas, ou seja, de preferência em horário em que estavam acompanhando os seus filhos aos atendimentos.

A entrevista foi realizada em uma das salas de atendimento da instituição por ser um local já familiar às mães, com duração aproximada de uma hora para cada uma delas.

Por ser uma pesquisa qualitativa, o número de participantes não foi previamente definido, pois o critério desse tipo de pesquisa não é numérico.

Na sétima entrevista, verificou-se que alguns dados já estavam repetitivos e considerou-se que já havia um número suficiente para se alcançar os objetivos propostos para a pesquisa. Sendo assim, adotou-se o critério de saturação, na qual o pesquisador encerra a coleta de dados quando as informações coletadas com certo número de sujeitos começam a se repetir ${ }^{9}$. Desta forma, constituiu-se como amostra sete mães.

Foi realizado o levantamento sociocultural das participantes da pesquisa e de seus respectivos filhos, com o intuito de contextualizar e fornecer subsídios para proceder às entrevistas. Esses dados são apresentados nos Quadros 1 e 2.

Quadro 1 - Caracterização sociocultural das participantes com relação à idade, profissão, escolaridade, estado civil e número de filhos

\begin{tabular}{|c|c|c|c|c|c|}
\hline Participante & Idade & Profissão & Escolaridade & Estado civil & Filhos \\
\hline M1 & 43 & Aposentada por invalidez & Ensino fundamental incompleto & Casada & 1 \\
\hline M2 & 30 & Reciclagem & Analfabeta & Solteira & 1 \\
\hline M3 & 40 & Do lar & Ensino fundamental incompleto & Casada & 2 \\
\hline M4 & 46 & Auxiliar de tapeçaria & Ensino médio completo & Solteira & 1 \\
\hline M5 & 45 & Do lar & Ensino fundamental incompleto & Casada & 2 \\
\hline M6 & 37 & Desempregada & Ensino fundamental incompleto & Amasiada & 3 \\
\hline M7 & 29 & Do lar & Ensino fundamental incompleto & Casada & 1 \\
\hline
\end{tabular}

Observou-se que a maioria das participantes (cinco mães) apresenta o mesmo grau de instrução (ensino fundamental incompleto) e mesmo nível socioeconômico. Duas mães estão atualmente inseridas no mercado de trabalho. Portanto, a proximidade das condições socioculturais das participantes da pesquisa, nos permite dizer que 0 acesso a informações por parte das mesmas ocorreu de forma semelhante, não sendo a escolaridade, então, fator determinante das respostas concedidas durante a entrevista.

No Quadro 2, são descritas as crianças surdas com relação à idade, grau de perda auditiva ${ }^{10}$, idade do diagnóstico da surdez e tempo de atendimento na instituição atual.

Quadro 2 - Caracterização das crianças surdas quanto à idade, grau de perda auditiva, idade do diagnóstico da surdez e tempo de atendimento na instituição atual.

\begin{tabular}{|c|c|c|c|c|}
\hline Criança & Idade & Classificação da perda auditiva & $\begin{array}{c}\text { Idade de } \\
\text { diagnóstico }\end{array}$ & $\begin{array}{c}\text { Tempo de atendimento } \\
\text { na instituição atual }\end{array}$ \\
\hline F1 & 8 & Neurossensorial bilateral de grau severo & $2 a 8 m$ & 4 anos \\
\hline F2 & 8 & Neurossensorial bilateral de grau profundo & $2 a$ & 5 anos \\
\hline F3 & 11 & $\begin{array}{c}\text { Neurossensorial de grau severo na orelha } \\
\text { direita e grau severo a profundo na orelha } \\
\text { esquerda }\end{array}$ & $2 \mathrm{anos}$ \\
\hline F4 & 14 & Neurossensorial bilateral de grau profundo & 1 a5m & 2 anos \\
\hline F5 & 14 & Neurossensorial bilateral de grau profundo & $11 \mathrm{~m}$ & 4 anos \\
\hline F6 & 9 & Neurossensorial bilateral de grau profundo & 2 dias & 6 anos \\
\hline F7 & 9 & Neurossensorial bilateral de grau profundo & $1 \mathrm{a} 11 \mathrm{~m}$ & 6 anos \\
\hline
\end{tabular}

Ao levar em consideração os objetivos do estudo, optou-se pela entrevista semiestruturada, que parte da elaboração de um roteiro, isto é, intencionalmente o pesquisador recolhe informações através das falas dos participantes ${ }^{11}$.

Em relação ao roteiro de entrevista, Minayo (2000) refere que este deve facilitar a abertura, amplia e aprofunda a comunicação. Constam apenas alguns itens que se tornam indispensáveis para o delineamento do objeto de estudo.

Para o presente estudo foi elaborado um roteiro de entrevista de acordo com os objetivos da pesquisa a fim de orientar a coleta de dados. Desta forma, o que não foi relatado espontaneamente pelos participantes, foi questionado 
pela entrevistadora. Os tópicos abordados foram: o processo de diagnóstico da surdez da criança; concepção de surdez após o diagnóstico; informações recebidas acerca das possíveis intervenções a serem realizadas no caso; aspectos norteadores da escolha por uma intervenção (Oralismo, Comunicação Total, Bilinguismo); concepção de surdez atualmente; comunicação entre os pais e a criança; relação da criança surda com outras. As entrevistas foram registradas por meio de gravações de áudio e posteriormente transcritas integralmente.

Vale ressaltar, que na coleta de dados, não ocorreu nenhum tipo de intercorrência que pudesse influenciar nos resultados do estudo.

Após a leitura das transcrições, os dados foram agrupados em categorias e a análise de conteúdo foi realizada. Essa análise permite que se trabalhe com um corpus reduzido de material, estabelecendo categorias mais sutis, nas quais é mais relevante a presença do que a frequência de um item ${ }^{12}$.

Na técnica de análise de conteúdo, a organização da análise é feita em torno de três pólos cronológicos: a pré-análise, a exploração do material e o tratamento dos resultados, que incluem a inferência e a interpretação ${ }^{12}$.

Aanálise empreendida foi do tipo temática e categorial ${ }^{12}$. Na etapa de categorização de dados, realiza-se a classificação de seus elementos constitutivos através de diferenciação e reagrupamento ${ }^{12}$, por meio de critérios de repetição e relevância dos itens apresentados, de acordo com os objetivos do estudo.

Tendo como referência a leitura dos dados coletados e os tópicos pré-estabelecidos no roteiro de entrevista, foram elaboradas três categorias, a saber: concepção de surdez no diagnóstico e após a intervenção; informações recebidas acerca das abordagens educacionais em surdez e escolha por uma delas; comunicação com a criança fora do ambiente terapêutico.

Com base nas categorias selecionadas, procedeu-se à análise dos dados de cada participante em cada categoria, para depois se agruparem os dados das sete participantes em todas as categorias, o que possibilitou conhecer as concepções de surdez na perspectiva de mães ouvintes com filhos surdos.

\section{Resultados e discussões}

\section{1 - Concepcão de surdez no diagnóstico e após a intervencão:}

Como as mães participantes deste estudo provavelmente não possuem o conhecimento teórico sobre as concepções de surdez, foram questionadas sobre suas idéias e opiniões em relação à surdez logo após o diagnóstico e como a vêem atualmente, sendo seus discursos analisados de forma a verificar as representações apresentadas e de qual modelo de concepção mais se aproximam. Desta forma, ao serem questionadas em relação à concepção de surdez que apresentavam no momento em que receberam o diagnóstico de seus filhos, três das sete mães entrevistadas (M4, M6 e M7) afirmaram que não haviam tido contato prévio com surdos e não tinham conhecimento anterior algum sobre o que é surdez e, portanto, não apresentavam uma concepção de surdez ou da pessoa surda:

"Eu fiquei perdida, né? Não sabia o que fazer, não tinha orientação,na verdade eu não sabia nem o que que era a surdez, né?" (M6)

O desconhecimento da surdez faz com que muitas pessoas a descrevam a partir de características comportamentais apresentadas por alguns sujeitos surdos, o que ocorreu com M3 que, por conviver com crianças surdas com comportamentos agressivos, relacionou a surdez a tal aspecto:

"Eu não sabia o que era, eu via os filhos da minha vizinha, que eram surdos, e eles eram nervosos, achei que era isso." (M3)

O surdo que apresenta falta de domínio de uma língua pode ter dificuldades cognitivas e afetivas, sendo comum a afirmação de que possuem problemas nesses aspectos e por vezes, sendo descritos como agressivos, imaturos, teimosos, explosivos, entre outros ${ }^{13}$. Atribuir tais adjetivos à personalidade do surdo leva a uma rotulação, parecendo que essas características são intrínsecas à surdez.

Diferentemente das mães anteriores, as participantes M1 e M2 representavam a surdez como a impossibilidade de ouvir e afirmavam que esta pode ser minimizada com o uso do Aparelho de Amplificação Sonora Individual (AASI), aproximando a audição do surdo à do ouvinte sem, no entanto, fazê-lo ouvir de forma semelhante a este. M2 refere: 
"Eu já via, já via em pessoal que assim, criança que não ouvia, já via mais ou menos esse acompanhamento, que a criança quando é surdo, que eles tem que passar por uma avaliação, depois usar esse aparelho, mas não vai tá assim ouvindo, não vai volta a ouvir igual nós não, pra eles tem um tempo, eles ouvir aquele som com aparelho, mas um som diferente do nosso" (M2).

Já M5, ao discorrer sobre sua concepção de surdez no momento em que recebeu o diagnóstico de seu filho, afirma que, ao contrário de seus pais e familiares, não designava à surdez a descrição de uma doença. Observa-se, em tal discurso, elementos que demonstram o reconhecimento da importância do uso de estratégias que estão de acordo com a diferença linguística do sujeito surdo, ainda que a participante acredite que seja difícil e cansativo levá-la em consideração na comunicação entre ouvintes e surdos:

"Não, eu já não pensava dessa forma, achava difícil, na surdez, a forma de comunicar,
porque imagine comunicar com uma criança só de frente, né?(...) aí como, de costa não
tinha como, tinha que tocar nela pra ela entender o que eu tava falando. Era difícil, mas eu
não pensava da forma que os meus pais pensavam, porque até hoje mesmo é mais difícil,
tem mais dificuldade, né? É difícil de lidar com surdo". (M5)

Alguns autores apontam, em contrapartida ao discurso acima, a necessidade da aceitação das diferenças existentes na modalidade de comunicação utilizada pelos surdos ${ }^{14}$. A visão da surdez como doença, como feito pelos pais da participante M5 está entre os principais fatores que levam à estigmatização do surdo.

Relacionando a fala da participante M2 com o modo de comunicação de seu filho, que se dá por meio da Língua Brasileira de Sinais (Libras), e com o uso que faz de recursos auditivos para obter a atenção da criança quando quer se dirigir à mesma, pode-se afirmar que, embora saiba que o filho não escuta como um ouvinte e privilegie a Língua de Sinais em sua comunicação com o mesmo, ainda não apresenta total conhecimento acerca das diferenças socioculturais entre o surdo e o ouvinte. Já a participante M3, ao definir como vê a surdez atualmente, refere:

"Agora eu penso que surdez é só não ouvir, né? Não é doença, não (...) é, eu acho que mudou o que eu penso porque eu vi como ela melhorou né? E porque conversaram muito comigo aqui também". (M3)

Esse trecho do discurso da mãe aparenta, em um primeiro momento, que ela se aproxima de uma visão sócioantropológica, pois deixa claro que a surdez não é doença e que "é só não ouvir", mas, tomando o discurso de toda a entrevista, constata-se que a mãe utiliza predominantemente a fala como meio de comunicação com a sua filha. Dessa forma, parece que a participante não tem uma concepção clara sobre surdez, pois como sua filha possui surdez severa e responde bem com o uso de AASI, ela não utiliza os sinais, pois acredita que a criança entende bem e consegue se expressar por meio da oralidade. Nota-se que apenas uma mãe revela uma concepção clara em seus discursos, aproximando-se da visão sócio-antropológica:

"É um jeito diferente mesmo, não tem nada de... Que impeça ele de fazer o que ele queira (...) ah, depois que eu conheci a Libras que eu não sabia que existia, depois que eu vim pra cá, que eu conheci tudo aqui, que (...) agora é normal pra mim". (M7).

Tal relato mostra que a mãe passou a acreditar que a surdez deve ser entendida como diferença e não como deficiência, afirmando que a concepção que apresenta agora se deve pelo contato com a Libras. Relacionando o discurso de M7 com a forma de comunicação que privilegia com seu filho, observa-se que esta põe em prática a ideia discorrida, utilizando a Língua de Sinais como principal meio de comunicação, aceitando que esta é sua língua natural e que suas diferenças não diminuem suas possibilidades e desempenhos quando comparado ao ouvinte.

Em contrapartida, a concepção clínico-terapêutica da surdez é a que mais se aproxima dos discursos das participantes M4 e M6: 
"Hoje, surdez, pra mim, é uma coisa normal, trato normal. Sim, gostaria que a minha filha falasse, porque ouvir, não por mim, é, mas pelo mundo, por mim não, normal, tranquilo, eu com a minha filha se entende muito bem, não tem dificuldade nenhuma, Deus vai abençoar, ela vai ser uma boa, né (...) boa, vai estudar, vai ser gente, né? Como se diz, na faculdade, mas eu tenho muita preocupação". (M4)

Observa-se, no trecho acima, a contradição presente no discurso da participante, pois, ao mesmo tempo em que afirma que a surdez seria algo normal e que compreende bem a filha, aponta também a crença de que Deus a ajudará para que possa estudar e se tornar "gente", deixando implícita a opinião de que existem incapacidades na criança surda, e que, sem o estudo, não seria uma pessoa "normal".

A participante M6, por sua vez, parece ter dificuldade em encontrar um termo para definir o que é surdez, como refere:

"É, é uma coisa que falta né, eu penso que é uma coisa que falta pra ele, pra, vamos dizer assim, ser como as outras pessoas, né?" (M6)

Afirmar que a surdez é algo que falta para que o sujeito seja como o ouvinte, é considerá-la como um desvio do padrão de normalidade, passando a retratar a criança surda, na maior parte do tempo, como alguém que está "a menos" em relação ao ouvinte ${ }^{15}$.

De forma diferente, M5 refere que a surdez não deve ser definida como doença, ou como deficiência mental, mas utiliza o termo "deficiente" ao mencionar o que entende por surdez. Ao mesmo tempo, parte de seu discurso aproximase da concepção sócio-antropológica, já que acredita na capacidade intelectual da criança, afirmando que a única impossibilidade da mesma é referente à audição:

"Ah, eu entendo como uma deficiência, né? Que até hoje eu vejo pessoas, até parentes meu, assim, mais distante, que tem a surdez como se fosse uma, um problema mental, né? Eu não acho isso, porque eu vejo a minha filha capacitada de fazer outras coisas, inteligente, aprende com facilidade, eu vejo a surdez só como o caso dela não ouvir. Se eu não tivesse um, se eu não tivesse uma filha surda, eu não ia saber o que é a surdez". (M5)

Este discurso revela certa confusão de conceitualização do que é a surdez e o sujeito surdo, de forma que, embora apresente ideias e atitudes que afirmam a diferença linguística e sociocultural dos mesmos, ainda utiliza-se do termo "deficiência" para se referir à surdez. É importante ressaltar que a questão do uso da nomenclatura "surdez" ou "deficiente auditivo" não é uma preocupação entre as pessoas leigas, ou mesmo entre as mães de crianças surdas, pois não percebem o que subjaz ao termo, e, assim, parecem utilizar comumente termos que são de senso comum.

Os discursos trazidos pela maioria das mães entrevistadas indicam a necessidade de se difundir a ideologia da surdez como diferença política, para que se possa conceituá-la adequadamente.

Ao afirmarem que a concepção de surdez que apresentam foi alterada pelas informações que receberam na instituição que frequentam, pelo contato com outras mães e pela observação da evolução de seus filhos, as participantes trazem à tona a importância das orientações e informações que recebem de profissionais, de forma que estas devem ser transmitidas de forma clara e cuidadosa para que sejam evitadas possíveis inseguranças, ansiedades, expectativas irreais e reações inadequadas, que podem ser prejudiciais tanto à família quanto à criança ${ }^{16}$.

\section{2 - Informações recebidas acerca das abordagens educacionais em surdez e escolha por uma delas:}

A depender do modelo de concepção de surdez adotado, existem diferentes possibilidades de intervenção na educação da criança surda, como, por exemplo, a abordagem oralista e a bilíngue, contando com uso de AASI ou Implante Coclear. A escolha dos pais neste âmbito é influenciada pelas informações e orientações que recebem durante o processo diagnóstico, assim como pelas atitudes dos profissionais envolvidos no caso e pelo acesso aos recursos disponíveis na comunidade ${ }^{16}$.

Em relação à escolha da abordagem educacional na (re)habilitação do filho surdo, todas as mães, exceto $M 4$, não receberam informações a respeito das diferentes abordagens e foram encaminhadas para locais específicos sem saber como trabalhavam.

Por exemplo, M2 e M7 foram encaminhadas diretamente para a instituição que frequentam atualmente: 
De forma análoga, M3 também não teve a possibilidade de escolher a abordagem do atendimento que a filha receberia, sendo encaminhada para a fonoaudióloga contratada pela prefeitura de sua cidade de origem: "Aí no exame deu que ela não escutava e ela foi pra fono da minha cidade." (M3)

Quando os pais escolhem o local de atendimento da criança, podem fazê-lo pela proximidade deste com a residência da família, como ocorreu no caso da mãe 6: "Me sugeriram três lugares, e aí eu preferi por ser mais perto de casa, né?" (M6)

Em contrapartida aos relatos anteriores, a participante M4 recebeu indicação de duas instituições em que sua filha poderia receber acompanhamento, sendo um na abordagem oralista e outro na abordagem bilíngue.

"Eu tinha que escolher, ou a U. (Clinica de Fonoaudiologia de uma Universidade), que tinha a Libras, ou só oral, na A. (Instituição Filantrópica para Deficientes)." (M4).

Parece que as informações que a mãe recebeu se restringiram ao uso da Libras ou a um trabalho com a oralidade, sendo este em uma instituição que trabalha com crianças com diversas deficiências, o que pode ter dificultado a escolha da participante. Alguns autores ressaltam a importância da atenção e da qualificação dos profissionais da área da saúde que estão envolvidos no processo de diagnóstico da surdez para que os pais recebam o apoio necessário e sejam realizados encaminhamentos e seguimentos adequados ${ }^{17}$.

Como as demais participantes, M1 e M6 afirmaram não ter recebido informações sobre as diferentes abordagens educacionais existentes, mas, na medida em que começaram a frequentar essa instituição, foram conscientizadas em relação ao ensino da Libras e as potencialidades de seus filhos. Essa explicação inicial, porém, não chegou a M3 e M4, sendo referido que os locais nos quais as filhas iniciaram atendimento não lhes passaram nenhum tipo de informação acerca do trabalho a ser realizado com a criança surda:

"Ela ficou lá até uns 7 anos, ai ela veio me falar que não dava mais pra trabalhar com a $N$. não, que ela não aprendia mais nada, ela nem sabia ler, nem escrever, nada. Aí ela mandou ela pra cá (...) não, não explicaram nada não". (M3)

"Não, não, eu tive todas as explicações foi em um Centro de Reabilitação (...) eu procurei pra fazer um implante, que a minha paixão era isso". (M4)

A participante M4, como se observa, passou a receber informações sobre as diferentes abordagens educacionais ao procurar atendimento em uma instituição oralista com a finalidade de submeter a filha à colocação do implante coclear:

"Então foi isso daí, eu ia nos dois lugares, na clínica de Fonoaudiologia perto da minha cidade (...) e ela me mostrava né, tinha uma instrutora surda, a R., que me mostrava que o implante coclear não era aquilo que eu pensava, e, então, e na minha cabecinha pequenininha, ela colocava o aparelho auditivo e ela ia sair falando". (M4)

Existe na literatura um estudo que mostra que, quando o diagnóstico não é informado adequadamente aos pais, há aumento de fantasias sobre as necessidades de seus filhos ${ }^{18}$. Assim, sendo o médico o profissional que primeiro confirma a suspeita da surdez apresentada pelos pais, torna-se necessário que ele garanta que estes não saiam de seu consultório com falsas expectativas quanto ao uso da prótese auditiva, uma vez que costumam acreditar que este substituirá a falha orgânica da criança ${ }^{19}$.

Sabe-se que existem controvérsias entre os profissionais em relação à abordagem de trabalho com a criança surda, e muitas vezes os pais ouvem opiniões contraditórias que acabam deixando-os confusos, como menciona M5:

"É, porque, a fono de lá, a moça que atendia ela lá, que fazia audiometria, falava pra mim que, se eu usasse os sinais, ia dificultar a fala, porque ela ia ficar com preguiça de falar, né? Isso eles me falaram, mas aqui já me falaram, assim, que a primeira língua dela é a Língua de Sinais, que se for tentar a fala dificulta, que se ela não tivesse a primeira língua, como que ela ia aprender a segunda, que é a fala, né?". (M5) 
O relato acima aponta a importância da orientação passada aos pais por parte dos profissionais que acompanham 0 caso, já que o ideal é que os pais sejam informados, no início da intervenção, da importância da Língua de Sinais, sendo enfatizadas as identidades culturais e políticas da criança surda.

Profissionais da saúde devem fornecer atenção aos pais, levando em conta seus sentimentos e os ajudando para que superem suas dificuldades ${ }^{2}$. Muitas vezes, porém, os profissionais não levam em conta o desejo que a família apresenta e acabam impondo um trabalho com a criança surda, como parece ter acontecido com a participante M4, que, apesar de estar inserida em uma instituição de abordagem bilíngue, buscou outro atendimento na tentativa de conseguir que sua filha recebesse o implante coclear, quando assistiu a uma reportagem na televisão. Ela menciona:

"Eu vi uma reportagem no Fantástico, do Centro Especializado em Malformações Craniofaciais, que tinha o implante coclear, eu fiquei, desesperada, eu vou fazer, eu vou fazer. Aí fui pra lá, vinha aqui, ia pra lá, porque a minha filha tinha que ouvir. Aí daqui a fonoaudióloga me mandou pra cidade vizinha, eu fui, mas eu queria o implante, queria. Aí tava tudo certo pra fazer o implante (...) ela não era candidata pra fazer implante". (M4)

Mesmo sendo informada de que a criança não era candidata ao implante coclear, M4 continuou a buscar instituições especializadas em tal procedimento, ainda que continuasse a frequentar a instituição bilíngue.

Através dos relatos dessa mãe, fica explícito seu desejo de que a filha ouça e, consequentemente, fale. Tal discurso aproxima-se da metodologia oral de educação do surdo, já que busca aproximar as condições de aquisição da linguagem do surdo às do ouvinte.

Por outro lado, temos o relato de M2, cujo filho estava na fila para a colocação de implante coclear e, no entanto, se recusou a submeter a criança a tal procedimento. Refere que conheceu uma criança que tinha passado por tal intervenção e não estava tendo resultados satisfatórios e, assim, decidiu continuar com o trabalho bilíngue realizado na instituição que frequentava:

"Ficou naquela lá, fila de transplante, de fazer, de ponha o transplante (...) na última hora, que tinha uns papeis pra assinar e eu falei que ele não ia fazer. Porque eu já tinha acompanhado criança com isso também, que eles rejeita. É, mas aí depois que eles me ligou pedindo pra eu levar ele lá, eu falei 'não, isso daí no meu filho eu não quero que faz, eu falei não, eu prefiro o aparelho". (M2)

O fato relatado por M2 mostra que a responsabilidade da escolha pelo implante coclear em crianças é dos pais, que devem determinar o que consideram melhor para seus filhos ${ }^{13,20}$.

Os dados aqui apresentados confirmam a importância da transmissão gradativa de informações para que a família escolha a instituição que considera mais adequada e, posteriormente, receba de forma mais detalhada os esclarecimentos acerca do que será trabalhado pelos profissionais envolvidos no caso.

\section{3 - Comunicação com a criança fora do ambiente terapêutico:}

A abordagem bilíngue tem como principal objetivo a criação de uma identidade bicultural que permite à criança surda o desenvolvimento de suas potencialidades dentro da cultura surda ${ }^{7}$. Ao estarem inseridos em uma instituição bilíngue, tanto os filhos surdos quanto suas mães têm acesso a duas modalidades de linguagem: a oral e a de sinais.

Observa-se uma estreita relação entre a concepção de surdez adotada e a modalidade de linguagem privilegiada pelos pais e seus filhos surdos dentro e fora do ambiente interdisciplinar que freqüentam ${ }^{21}$.

Com o objetivo de verificar se a modalidade de linguagem utilizada no ambiente terapêutico é também utilizada nos ambientes familiar e escolar, perguntou-se às participantes como se dava a comunicação da criança com seus pais, irmãos, outros familiares e amigos em seu dia-a-dia. Verifica-se que, enquanto M1 e M3 utilizam apenas a fala como forma de comunicação, já que seus filhos apresentam surdez de grau severo e suas falas são inteligíveis aos familiares, as demais optam pelo uso da Libras associada à língua oral quando se dirigem a seus filhos.

Além de afirmar que utiliza apenas a fala como forma de comunicação com sua filha, M1 apresenta o hábito de fazer a criança repetir palavras e responder a perguntas, objetivando testar 0 aprendizado da oralidade por parte da filha:

"Assim, a gente conversa, não uso Libras pra ela, converso com ela direitinho. Eu gosto de conversar, dar perguntinha pra ela e ela responde (...) é, o pai conversa com ela, né? Faz bastante perguntinha. Fala muitas palavras diferentes pra ela, ela repete tudo, né?". (M1) 
Já a participante M2 é exemplo daquelas que referem utilizar tanto a fala quanto a Língua de Sinais:

"É, eu falo, tem hora que ele tá de costas viradas, assim, de costas viradas fazendo alguma coisa, eu falo e ele olha pra mim. Aí quando ele tá olhando pra mim é sinais, mas ele faz os sinais também, ele presta atenção nos sinais e, ao mesmo tempo, ele faz que ele ouve, faz que ele tá ouvindo. Ele faz os sinais que ele tá ouvindo".(M2)

Embora afirme utilizar a Libras como principal meio de comunicação com seu filho, M2 demonstra que utiliza estratégias orais para iniciar o diálogo com a criança, chamando-a apenas com o uso da voz para, em seguida, utilizar os sinais.

Autores afirmam que os pais ouvintes que defendem a importância da aprendizagem da Libras, utilizando-a para facilitar a comunicação com a criança surda, são aqueles que apresentam maior grau de aceitação da surdez ${ }^{22}$. Desta forma, pode-se dizer, a partir da conduta relatada por M2, que a mãe não está totalmente habituada à comunicação bilíngue e que a surdez de seu filho não foi totalmente aceita, uma vez que não utiliza predominantemente a Língua de Sinais. A participante M4, por sua vez, afirma que considera a surdez algo normal e que comunica com sua filha por meio da fala e de sinais:

"Normal, eu não tô falando com você? Eu falo com a minha filha, com a boca e com a mão." (M4)

Embora o discurso da participante acima traga elementos que poderiam ser relacionados à concepção sócioantropológica da surdez, já que utiliza as duas línguas para se comunicar com a criança, sabe-se que tal mãe, em outros relatos, (discutidos na primeira categoria), demonstra idéias e atitudes que mais se aproximam de uma concepção clínico-terapêutica, já que continua a afirmar seu desejo de que a filha falasse e utilizasse o implante coclear, além de deixar implícita a opinião de que a criança surda apresenta incapacidades, se comparada à ouvinte.

Ainda que as famílias das crianças surdas tenham possibilidades de acesso a aulas de Língua de Sinais, nestes casos oferecidos pela instituição, a realidade é que apenas os responsáveis por levá-las à instituição é que acabam entrando em contato com a nova língua. Desta forma, a comunicação dessas crianças no ambiente familiar, na escola ou com seus amigos ouvintes pode se dar, muitas vezes, pelo uso da oralidade e por gestos caseiros.

Outro fato trazido no depoimento da participante M5 é o hábito de ensinar Libras a outros membros da família:

"Se ela quer saber alguma coisa, ela vem perguntar pra mim, a priminha dela vem perguntar, e ela acaba aprendendo, e como as duas passam muito tempo juntas quando ela vem pra cá e quando ela vai pra casa dela, então ela aprende comigo também". (M5)

Definindo o intérprete como aquele que se coloca entre o produtor e o consumidor de uma língua, pode-se dizer que, ainda que de forma informal, as mães conhecedoras da Libras acabam permeando a comunicação entre seus filhos surdos e os familiares e amigos que desconhecem tal língua.

\section{Considerações Finais}

Nesse estudo, verificou-se que a escassez de informações e conhecimentos acerca da surdez não permitiu o conhecimento e a escolha das mães por uma das abordagens de trabalho com surdos, assim como impossibilitou a maioria delas de ter uma concepção clara sobre surdez logo após o diagnóstico de seus filhos.

A maioria das mães deste estudo apresentou uma concepção de surdez que oscila entre a sócio-antropológica e a clínicoterapêutica, trazendo relatos e atitudes que se contradizem. Afirmam a importância da Língua de Sinais como meio de comunicação, mas não reconhecem as diferenças socioculturais, políticas e linguísticas dos surdos. Acredita-se que, nesses casos, as participantes, por não terem conhecimento teórico sobre surdez, apresentam dificuldades em internalizar conceitos e idéias teóricas, tendo a representação de surdez contagiada pelas crenças da sociedade em que estão inseridas, de forma que os sentidos de valores construídos coletivamente influenciam fortemente o conceito destas mães.

Frente à impossibilidade de escolha da instituição e da abordagem educacional em que os filhos foram inseridos, acredita-se que continuam a frequentar a instituição bilíngue por observarem os progressos dessas crianças, e não por reconhecerem a ideologia da identidade surda e seu biculturalismo. 
Nota-se, aqui, a importância do adequado acolhimento da família quando o diagnóstico de surdez de seus filhos é dado para que possam receber todas as informações pertinentes, já que a possibilidade de escolha da abordagem a ser seguida, certamente influenciará na aceitação da surdez em todos os seus aspectos (linguísticos, políticos, sociais, culturais).

\section{Referências Bibliográficas}

1. Demetrio SES. Deficiência auditiva e família. In: Bevilacqua MC, Moret ALM (Orgs.), Deficiência auditiva: conversando com familiares e profissionais da saúde. São José dos Campos: Editora Pulso, 2005.

2. Lemes LC, Barbosa MAM. Reações manifestadas pelas mães frente ao nascimento do filho com deficiência. Rev Soc Bras Enferm. 2008;8(1),31-36.

3. Silva ABP, Pereira MCC, Zanolli ML. Surdez: relato de mães frente ao diagnóstico. Estudos de Psicologia. 2008;13(2),175-183.

4. Negrelli MED, Marcon SS. (2006). Família e Criança Surda. Ciência, Cuidado e Saúde. 2006;5(1),98-107.

5. Lanzetta BP, Frota S, Goldfeld M. Acompanhamento da adaptação de próteses auditivas em crianças surdas. Rev CEFAC. 2010;12(3), 360-370.

6. Corghi PRMC. Pais surdos e filhos ouvintes: funcionamento familiar, convivência e relacionamento. (Trabalho de Conclusão de Curso de Psicologia, Pontifícia Universidade Católica de São Paulo, São Paulo). 2006.

7. Skliar C. Uma perspectiva sócio-histórica sobre a psicologia e a educação dos surdos. In: Skilar C. (Org), Educação e exclusão: abordagens sócio-antropológicas em educação especial (pp. 105-153). Porto Alegre: Mediação, 2000.

8. Denzin, NK. \& Lincoln, YS. A disciplina e a prática da pesquisa qualitativa. In: Denzin, NK., Lincoln, YS. e cols. (Orgs), 0 planejamento da pesquisa qualitativa: teorias e abordagens (Tradução S. R. Netz) (pp. 15-41). Porto Alegre: Artmed, 2006.

9. Turato, ER. Tratado da metodologia da pesquisa clínico-qualtitativa: construção teórico-epistemológica, discussão comparada e aplicação nas área da saúde e humanas. Petrópolis: Vozes, 2003.

10. Silman S., Silverman MAN. Auditory Diagnoses. San Diego: Academic Press, 1991.

11. Minayo MCS. O desafio do conhecimento: pesquisa qualitativa em saúde. 7.ed. Rio de Janeiro: Hucitec-Abrasco, 2000.

12. Bardin L. Análise de conteúdo. 4.ed. Lisboa: Edições 70, 2004.

13. Silva ABP. Surdez, inteligência e afetividade. In I. R. Silva, S. Kauchakje, \& Z. M. Gesueli (Orgs.), Cidadania, surdez e linguagem:desafios e realidades, ( $3^{\mathrm{a}}$ ed.) (pp. 89-97). São Paulo: Plexus Editora. 2010.

14. Dizeu LCTB, Caporali SA. A língua de sinais constituindo o surdo como sujeito. Educação e Sociedade. 2005;91(26), 583-597.

15. Bisol C, Sperb TM. Discursos sobre a Surdez: Deficiência, Diferença, Singularidade e Construção de Sentido. Psicologia: Teoria e Pesquisa. 2010;26(1), 7-13.

16. Motti TFG, Pardo MBL. Intervenção com pais de crianças deficientes auditivas: elaboração e avaliação de um programa de orientação não presencial. Rev Bras Educação Especial. 2010;16(3), 447-462.

17. Silva ABP, Pereira MCC, Zanolli ML. Surdez: da suspeita ao encaminhamento. Rev Paul Pediatr. 2012;30(2), 257-262.

18. Silva NLP, Dessen MA. Crianças com Síndrome de Down e suas interações familiares. Psicologia: Reflexão e Crítica. 2003;16(3), 503-514.

19. Gilbey P. Qualitative analysis of parents' experience with receiving the news of detection of their child's hearing loss. International Journal of Pediatric Otorhinolaryngology. 2010;74(3), 265-270.

20. Yamanaka DAR, Paiva e Silva RB, Zanolli, AL, Silva ABP. Implante coclear em crianças: a visão dos pais. Psicologia: Teoria e Pesquisa. 2010;26(3), 1-10.

21. Silva ABP, Pereira MCC, Zanolli ML. Mães Ouvintes com Filhos Surdos: Concepção de Surdez e Escolha da Modalidade de Linguagem. Psicologia: Teoria e Pesquisa. 2007;23(3), 279-286.

22. Rodrigues AF, Pires A. Surdez infantil e comportamento parental. Análise Psicológica. 2002;30(XX), 389-400. 


\section{Gabriela de Paula Teixeira}

Endereço para correspondência - Rua: Fortunato Milane, $n^{\circ}$ 61, Bairro: Bela Vista, CEP: 13207-722, Cidade: Jundiaí, SP, Brasil.

E-mail: gpt.fono@hotmail.com

Lattes: http://lattes.cnpq.br/304665642107752

Angélica Bronzatto de Paiva e Silva - arbps@fcm.unicamp.br

Maria Cecilia Marconi Pinheiro Lima - ceclima@fcm.unicamp.br

Enviado em 10 de fevereiro de 2014.

Aceito em 19 de março de 2015. 
